\title{
Juice chemical properties of 24 sorghum cultivars under varying levels of sugarcane aphid (Melanaphis sacchari) infestation
}

\author{
Joseph E. Knoll ${ }^{1}\left[\right.$ : Minori Uchimiya ${ }^{2}\left([) \cdot\right.$ Karen Harris-Shultz $^{1}(\mathbb{0}$
}

Received: 4 May 2021 / Accepted: 8 July 2021 / Published online: 6 September 2021

(c) This is a U.S. government work and not under copyright protection in the U.S.; foreign copyright protection may apply 2021

\begin{abstract}
Sugarcane aphids [Melanaphis sacchari (Zehntner)] have become a significant pest of grain, forage, and sweet sorghum [Sorghum bicolor (L.) Moench] in the USA in recent years. However, the effects of sugarcane aphid damage on sweet sorghum juice quality have not been well studied. A three-year (2015-2017) field study was conducted at Tifton, GA to assess planting date effects (April, May, or June planting) and cultivar responses (24 cultivars) to sugarcane aphids in sorghum. Aphid damage ratings were measured in all three years and cumulative aphid days were measured in 2016 and 2017. Cumulative aphid days (ln scale) and damage ratings (relative marginal effect) were correlated in five of the six plantings. Stem juice was collected at maturity from seven plantings for chemical analyses, which included HPLC, fluorescence excitationemission spectrophotometry with parallel factor analysis (EEM/PARAFAC), and cyclic voltammetry (CV). Aphid damage ratings and cumulative aphid days were negatively correlated with sugar-related traits, particularly brix and total sugars. In four plantings, significant negative correlations $(r \leq-0.493)$ between trans-aconitic acid concentration and aphid damage were observed. Fluorescence and electrochemical properties related to the presence of polyphenols also showed correlations with aphid damage, particularly in the resistant landrace No. 5 Gambela. These secondary metabolites may play a role in sugarcane aphid resistance or tolerance. Stability analysis revealed that the more tolerant cultivars were able to maintain high concentrations of total sugars and trans-aconitic acid across environments.
\end{abstract}

Keywords Antioxidant $\cdot$ Chemometrics $\cdot$ Cumulative aphid days $\cdot$ EEM/PARAFAC $\cdot$ Stability analysis $\cdot$ Trans-aconitic acid

\section{Introduction}

The sugary juice pressed from the stalks of sweet sorghum (Sorghum bicolor (L.) Moench) is traditionally boiled to produce a sweet edible syrup (Winberry 1980). It also has potential uses for biofuel production (Davila-Gomez et al. 2011; Hills et al. 1990) and in the manufacturing of other

Communicated by Ritu Chaudhary.

Joseph E. Knoll

joe.knoll@usda.gov

Minori Uchimiya

sophie.uchimiya@usda.gov

Karen Harris-Shultz

karen.harris@usda.gov

1 USDA-ARS Crop Genetics and Breeding Research Unit, 115 Coastal Way, Tifton, GA 31793, USA

2 USDA-ARS Southern Regional Research Center, 1100 Robert E. Lee Boulevard, New Orleans, LA 70124, USA 'bio-based' products (Andrzejewski et al. 2013). There is a need to develop improved sweet sorghum cultivars, particularly hybrids, but environmental factors such as planting date can influence selection of superior cultivars. Thus, in 2015, we conducted a sorghum cultivar by planting date study at Tifton, GA, in which 23 mostly sweet inbred and hybrid entries were planted in April, May, and June (Knoll et al. 2018). At maturity, juice samples were collected in order to investigate chemical properties of the juice and to develop rapid chemical detection techniques. Such techniques could hasten selection for development of superior sweet sorghum cultivars. Fluorescence excitation-emission spectrophotometry with parallel factor analysis (EEM/PARAFAC) was utilized to identify three fluorescent chemical fingerprints in sorghum juice: a tyrosine-like, a tryptophan-like, and an aromatic fingerprint representing polyphenolic structures (Uchimiya et al. 2017a). Correspondingly, we have also developed cyclic voltammetry (CV) techniques to explore the electrochemical properties of sorghum juice (Uchimiya et al. 2017b). In addition to traditional high-performance 
liquid chromatography (HPLC), these techniques were used to identify differences in chemical properties across cultivars and planting dates (Uchimiya et al. 2017a, b).

During the course of this experiment, approximately late June 2015 the sugarcane aphid [Melanaphis sacchari (Zehntner)], a new insect pest of sorghum in North America, began to infest the sorghum plots. Infested plots were observed in the late summer of 2014, but 2015 was the first full growing season with this pest widespread in Georgia. Sugarcane aphid populations can build quickly, and damage symptoms include leaf discoloration and desiccation, delayed flowering, and reduced yields (Bowling et al. 2016). Sugarcane aphid infestation can also cause reductions in grain quality (Bowling et al. 2016; Singh et al. 2004) but its effects on sweet sorghum juice quality have not been well studied.

In North America the sugarcane aphid genotype that infests sorghum (known as multi-locus lineage F (MLL-F); Nibouche et al. 2018) does not survive well on sugarcane (Saccharum spp.) (Paudyal et al. 2019). However, it does overwinter on Johnsongrass [S. halepense (L.) Pers.] and volunteer or ratoon sorghum in regions where temperatures remain above freezing (Bowling et al. 2016). They have also been reported on Columbus grass (S. $\times$ almum Parodi) (Paudyal et al. 2019) and giant miscanthus [M. $\times$ giganteus (Greef et Deu ex. Hodkinson et Renvoize)] (Harris-Shultz and $\mathrm{Ni} 2021$ ). In the spring, alates (winged aphids) migrate north to infest the new sorghum crop (Bowling et al. 2016). Thus, in temperate regions early planting has been suggested as one strategy to minimize damage from sugarcane aphid (Szczepaniec 2018; Haar et al. 2019; Seiter et al. 2019), as chemical control options for this pest are limited, particularly in sweet sorghum. The planting date study at Tifton, GA was thus repeated in 2016 and 2017 to determine if planting date could indeed be altered to avoid aphid damage. Each year (2015-2017) sorghum was planted in April, May, and June and each year the sugarcane aphids arrived in mid to late June. This was followed by a sharp population increase over several weeks in July, and then a rapid population collapse, which appears to be caused by a fungal entomopathogen (Haar et al. 2018), resulting in the aphids mostly disappearing by August each year. As a result of the aphid population collapse, which typically occurred prior to flowering of the June-planted crop, this last planting consistently suffered less damage than the earlier two plantings (Knoll et al. 2019).

In our breeding nursery in 2015 we observed strong sugarcane aphid resistance in an Ethiopian landrace called No. 5 Gambela (PI 257599), thus we added this accession to the planting date experiments in 2016 and 2017. It was observed that the juice of this cultivar accumulated the greatest concentrations of trans-aconitic acid, as well as quercetin-like polyphenolic secondary metabolites, compared to the other
23 cultivars (Uchimiya and Knoll 2018, 2019a). In the 2017 planting date study, a negative correlation between aphid damage rating and juice trans-aconitic acid concentration was also observed, suggesting a possible role of this metabolite in aphid tolerance or resistance (Uchimiya and Knoll 2019a).

In the current study we utilized all available data from the three-year planting date study to correlate juice chemical traits with sugarcane aphid population (as cumulative aphid days) or visual damage ratings. The purpose was to determine which chemical traits of sorghum juice are most affected by sugarcane aphid (or vise-versa). The most important chemical traits were then subjected to a cultivar stability analysis (Eberhart and Russell 1966) to determine which cultivars, if any, respond differently to changing environments, with the major environmental constraint assumed to be the level of aphid infestation and damage. The goals of this work were to identify aphid-tolerant germplasm or sweet sorghum cultivars and possible biochemical aphid defense markers or mechanisms for further study.

\section{Materials and methods}

\section{Field experiment and juice collection}

The field experimental design has been described in detail previously (Uchimiya et al. 2017a, b; Uchimiya and Knoll 2018). Briefly, each year $(2015,2016$, and 2017) a split-plot experiment with three replications was conducted at Tifton, GA, USA $\left(31^{\circ} 30^{\prime} \mathrm{N}, 83^{\circ} 32^{\prime} \mathrm{W}\right)$ in which planting date (April, May, or June; referred to as Plantings 1, 2, and 3, respectively) served as the main plot factor with 23 sorghum cultivars (inbred lines and derived hybrids) randomly arranged as sub-plots. The inbred cultivars were: Atlas (PI 641807), Chinese, Dale (PI 651495; Broadhead and Coleman 1973), Isidomba (PI 144331), N98 (PI 535783), N109B (PI 535794), N110B (PI 535795), and N111B (PI 535796; Gorz et al. 1990). The hybrids included all possible crosses between the first five inbred lines and the A-line (male-sterile) versions of N109, N110, and N1111. These accessions all have juicy stems (approx. 70\% moisture) and are capable of attaining Brix of around $14^{\circ} \mathrm{Bx}$ or higher (Knoll et al. 2018). In 2016 and 2017 the sugarcane aphid-resistant landrace No. 5 Gambela (PI 257599) was added, for a total of 24 entries. Sugarcane aphid damage was rated on a 1-9 scale of increasing damage severity, as described by Sharma et al. (2014), where 1 indicates no damage and 9 indicates dead, or nearly dead, plants. Damage was rated on two to seven occasions for each plot, beginning when significant aphid population growth was observed and continuing every two weeks until juice collection. In 2016 and 2017 aphid population was rated at the same times as damage. Aphid population was 
rated on a semi-logarithmic scale: 0 aphids leaf ${ }^{-1}, 25$ aphids leaf $^{-1}, 50$ aphids leaf ${ }^{-1}, 100$ aphids leaf ${ }^{-1}, 500$ aphids leaf ${ }^{-1}$, 1000 aphids leaf ${ }^{-1}$, and 5000 aphids leaf ${ }^{-1}$. The number of aphids was estimated on the lowest green leaf and the second leaf from the top of the plant, and an average of these was taken for analysis. Aphid days were calculated for each sampling period as the average number of aphids multiplied by the length of the sampling period (14 days). Cumulative aphid days for the season were then calculated by summing aphid days from all sampling periods (Ruppel 1983).

Juice was collected at the hard-dough stage of maturity (approximately 30 days after anthesis) by pressing three stripped stalks twice through a roller mill (Sor-Cane Porta Press, McClune Industries, Reynolds, GA). This mill extracts approximately $36 \%$ of the total stalk moisture as juice. The juice was immediately frozen for storage and shipment. Juice was collected for all three plantings in 2015 and 2017, and for the May planting only in 2016.

\section{Juice chemistry}

Frozen juice was sent to the USDA-ARS Southern Regional Research Center in New Orleans, LA, where chemical characterization procedures were conducted. Briefly, sugars and organic acids were quantified by HPLC. Total organic carbon (TOC) and total nitrogen (TN), in $\mathrm{g} \mathrm{L}^{-1}$ of $\mathrm{C}$ and $\mathrm{N}$, respectively, were measured by combustion and gas phase analyses. The $\mathrm{pH}$, electric conductivity (EC), and reduction potential $\left(E_{h}\right)$ of the juice samples were determined using dedicated electrodes. Specific instruments and procedures are described in detail by Uchimiya et al. (2017a, b) and Uchimiya and Knoll (2018). Fluorescence excitation-emission (EEM) spectra of juice samples at 220-500 nm excitation and 280-730 nm emission wavelengths were obtained with an F-7000 spectrofluorometer (Hitachi, San Jose, CA). Spectra were analyzed by a parallel factor analysis (PARAFAC) of data sets complied for the present study (93 core consistency). A detailed description of the EEM/PARAFAC procedure is given by Uchimiya et al. $(2017 \mathrm{a}, \mathrm{b})$ and Uchimiya and Knoll (2018). Electrochemical properties of juice samples were examined by cyclic voltammetry (CV), as described by Uchimiya et al. (2017b) and Uchimiya and Knoll (2018). Areas under the anodic potential curves from CV experiments were modeled by Gaussian fitting, where the apex voltage was designated the peak anodic potential $\left(\mathrm{E}_{\mathrm{pa}}\right)$. Trapezoidal integration was separately performed to account for minor anodic peaks.

\section{Statistical analyses}

Statistical procedures were conducted using SAS v. 9.4 (SAS Institute, Cary, NC). Chemical data were analyzed by analysis of variance (ANOVA) using the GLIMMIX procedure, with cultivar, environment, and their interaction as fixed effects, where 'environment' refers to one of seven specific plantings (2015-1, 2015-2, 2015-3, 2016-2, 2017-1, 2017 2, and 2017-3) where chemical data were taken. Post hoc least squares (LS) means comparisons were conducted using Tukey's HSD at $\alpha=0.05$. Due to differences in the number of sampling dates each year, the sugarcane aphid damage ratings were analyzed separately for each year with planting date, cultivar, and sampling date as fixed effects. The damage ratings were first converted to ranks using the SORT and RANK procedures. The ranks were then analyzed by repeated-measures ANOVA using the MIXED procedure. The resulting midrank values were converted to relative marginal effects (values between 0 and 1, inclusive) as described by Shah and Madden (2004). Cumulative aphid days were also analyzed by individual year, with planting date, cultivar, and their interaction as fixed effects, and were modeled using the lognormal distribution in the GLIMMIX procedure of SAS and are thus reported on the natural $\log (\ln )$ scale.

Correlation analyses were conducted on the LS means in the CORR procedure of SAS to explore potential relationships between aphid damage rating (as relative marginal effects) or cumulative aphid days (ln scale) versus various juice chemical properties in the environments for which data were available. Separate correlations were calculated for each environment. Also, because cultivar No. 5 Gambela often had the most extreme chemical phenotype, and as an outlier could thus produce artificially high correlations, the correlation analyses were repeated without this cultivar and the results were compared.

Stability analysis was conducted as described by Eberhart and Russell (1966) in the GLM procedure of SAS as an analysis of covariance (ANCOVA). Cultivar $\times$ environment LS means were regressed against the environmental indexes (grand mean minus environmental mean), with cultivar as a class variable. Where there was a significant interaction between cultivar and environmental index, slopes $(b)$ for each cultivar were calculated with ESTIMATE statements. A slope close to 1 indicates that a cultivar has an 'average' response to the environment, whereas a slope near zero indicates that a cultivar does not respond to changes in environmental conditions. By default, SAS performs a test on each slope to determine if it is significantly different from zero.

\section{Results}

\section{Planting date and cultivar effects on sugarcane aphids}

In each year of this experiment, the first planting received the highest mean damage rating, followed by the second planting, and the third planting received the lowest mean 
damage rating (Fig. 1), and all differences between plantings were significant. This appears to be a result of the aphid population collapse that occurred each year in August, prior to the average flowering date of the third planting, which has been previously reported (Knoll et al. 2019). Cumulative aphid days were measured in 2016 and 2017 (Figs. 2 and 3), and they partly reflect this trend. In 2016, the later planting resulted in numerically fewer cumulative aphid
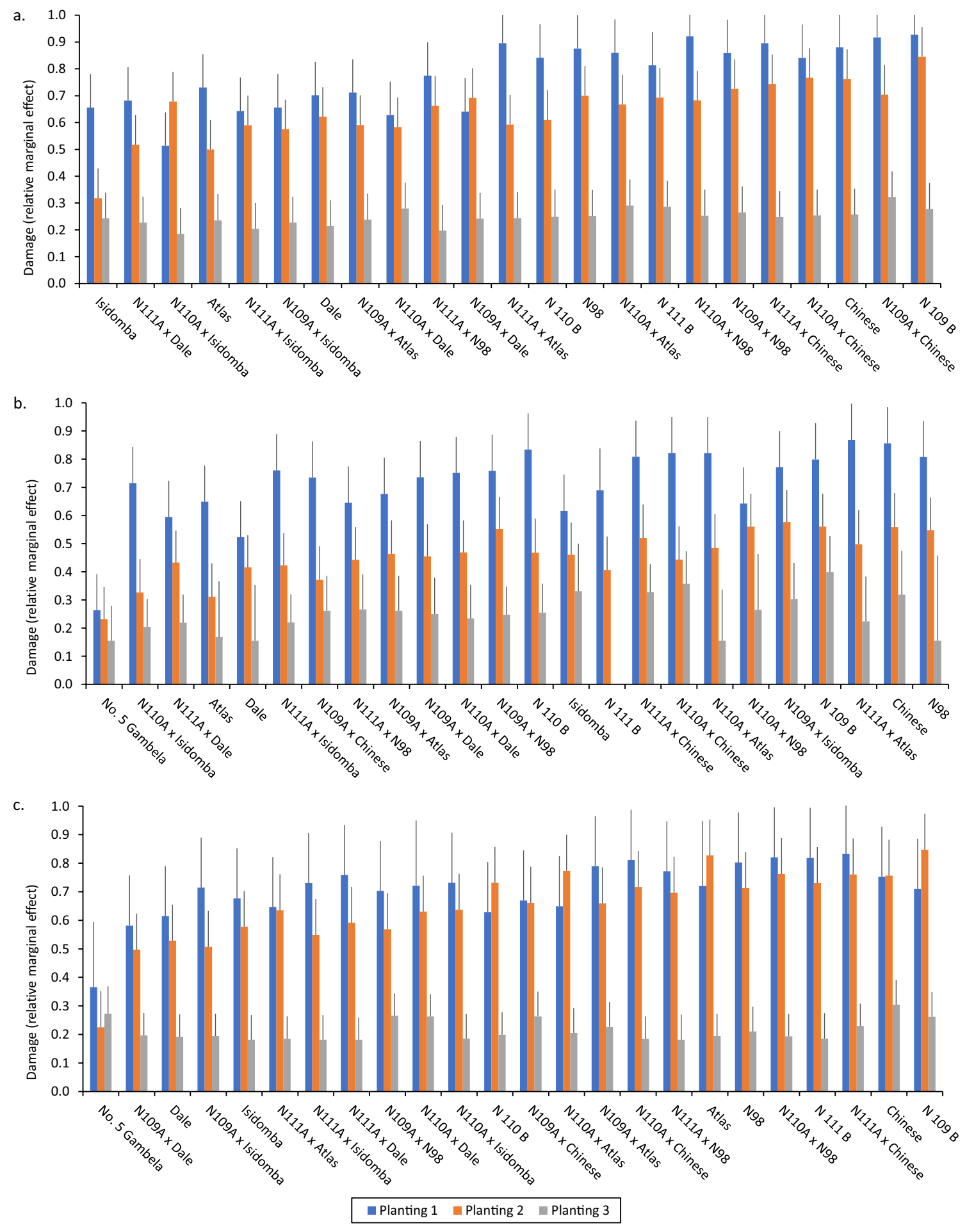

Fig. 1 Average sugarcane aphid damage ratings (expressed as relative marginal effects) for sorghum cultivars sown in April (Planting 1), May (Planting 2), and June (Planting 3), in years a 2015, b 2016, and c 2017 at Tifton, GA. Error bars represent approximate 99\% confidence intervals; for clarity, only upper bars are shown 
Fig. 2 Linear relationships between cumulative aphid days (ln scale; $x$-axes) and sugarcane aphid damage ratings (relative marginal effects; $y$-axes) for 24 sorghum cultivars sown in April (Planting 1), May (Planting 2 ), and June (Planting 3), in years a 2016 (overall $r=0.574$, $p<0.0001$ ) and b 2017 (overall $r=0.912, p<0.0001)$ at Tifton, GA. The aphid-resistant cultivar No. 5 Gambela is represented by triangles a.

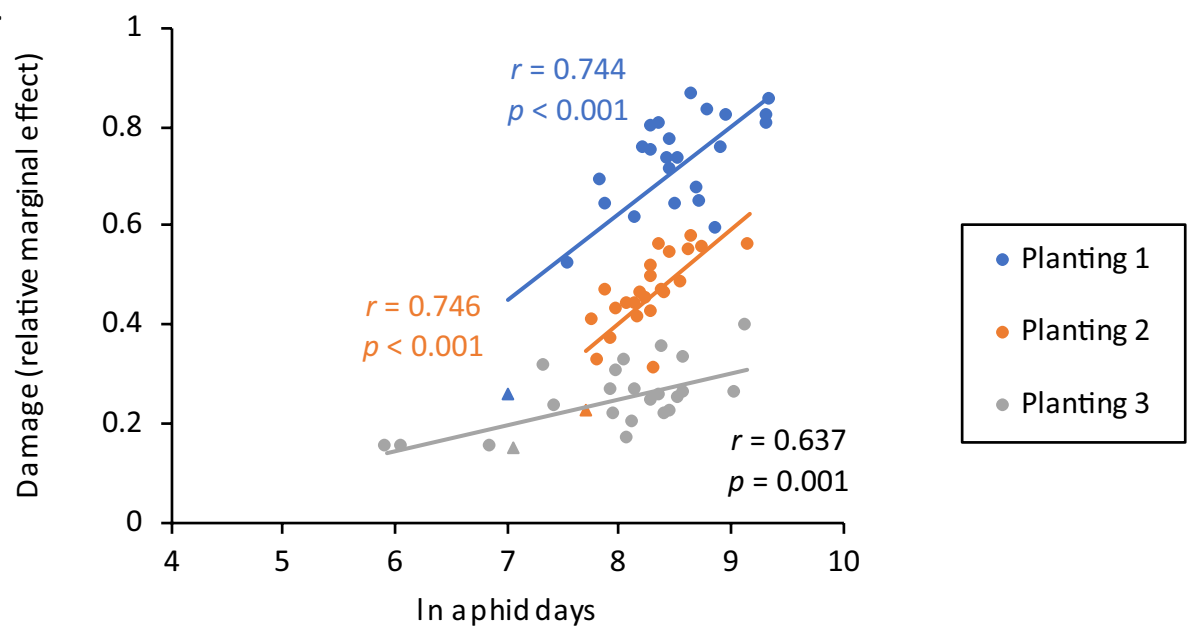

b.

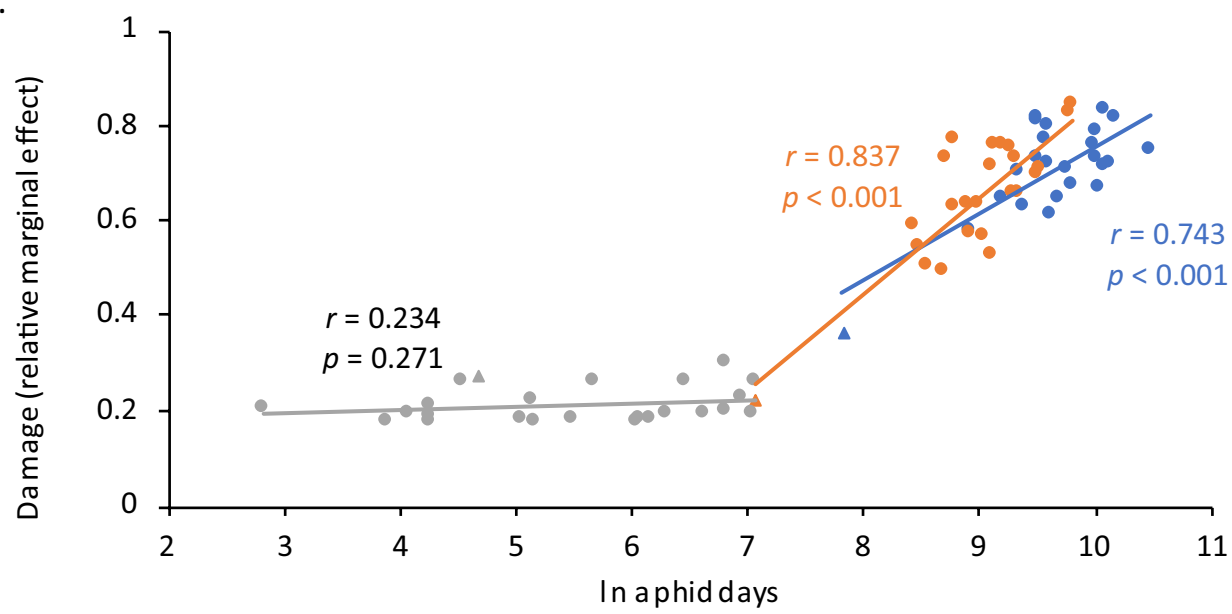

days (In aphid days $=8.48,8.27$, and 7.94 in Plantings 1, 2 , and 3 , respectively), but the differences between plantings were not statistically significant $(F=1.33, p=0.360)$. However, across all three plantings in 2016 there was a modest correlation between damage rating and cumulative aphid days $(r=0.574, p<0.0001)$, and within each individual planting, damage rating and cumulative aphid days were strongly correlated ( $r \geq 0.637, p<0.0001$; Fig. 2a). In 2017 mean cumulative aphid days were significantly lower in planting 3 (ln aphid days $=5.46$ ) than in plantings 1 and 2 (In aphid days $=9.64$ and 8.98, respectively). Across all three plantings in 2017, damage rating and cumulative aphid days were strongly correlated $(r=0.912, p<0.0001)$. Within individual plantings, these two variables were again correlated, except in the last planting, where they did not correlate because damage ratings were negligibly low for all cultivars (Fig. 2b).

The various cultivars showed different levels of sugarcane aphid damage in all three years of the study, and interactions with planting date were significant. In 2015 the cultivars with the greatest damage included N109B, the inbred line Chinese, and hybrids of Chinese. Least damaged cultivars included Isidomba, Dale, and hybrids of Dale, though this varied somewhat by planting date as shown in Fig. 1a. Within the third planting, where overall damage was low, differences among cultivars were not significant. In 2016 and 2017, the aphid-resistant line No. 5 Gambela had consistently lower aphid damage ratings than most other cultivars in the first and second plantings. Cultivar damage rankings were less consistent between plantings in 2016 as shown in Fig. 1b, though Dale was still among the least damaged and Chinese and N109B among the most damaged. In 2016 cultivars No. 5 Gambela, Dale, and N98 were among those with the fewest cumulative aphid days on average, while N109B had the most (Fig. 3a). Interactions between cultivar and planting date were also significant in 2016 for cumulative aphid days $(F=1.87, p=0.004)$. Damage ratings in 2017 were more similar to 2015 in that cultivars Dale, Isidomba, and their hybrids were again among the least damaged and Chinese and N109B were again among those with the greatest damage (Fig. 1c). Cumulative aphid days showed some numerical differences among cultivars, but they could not 

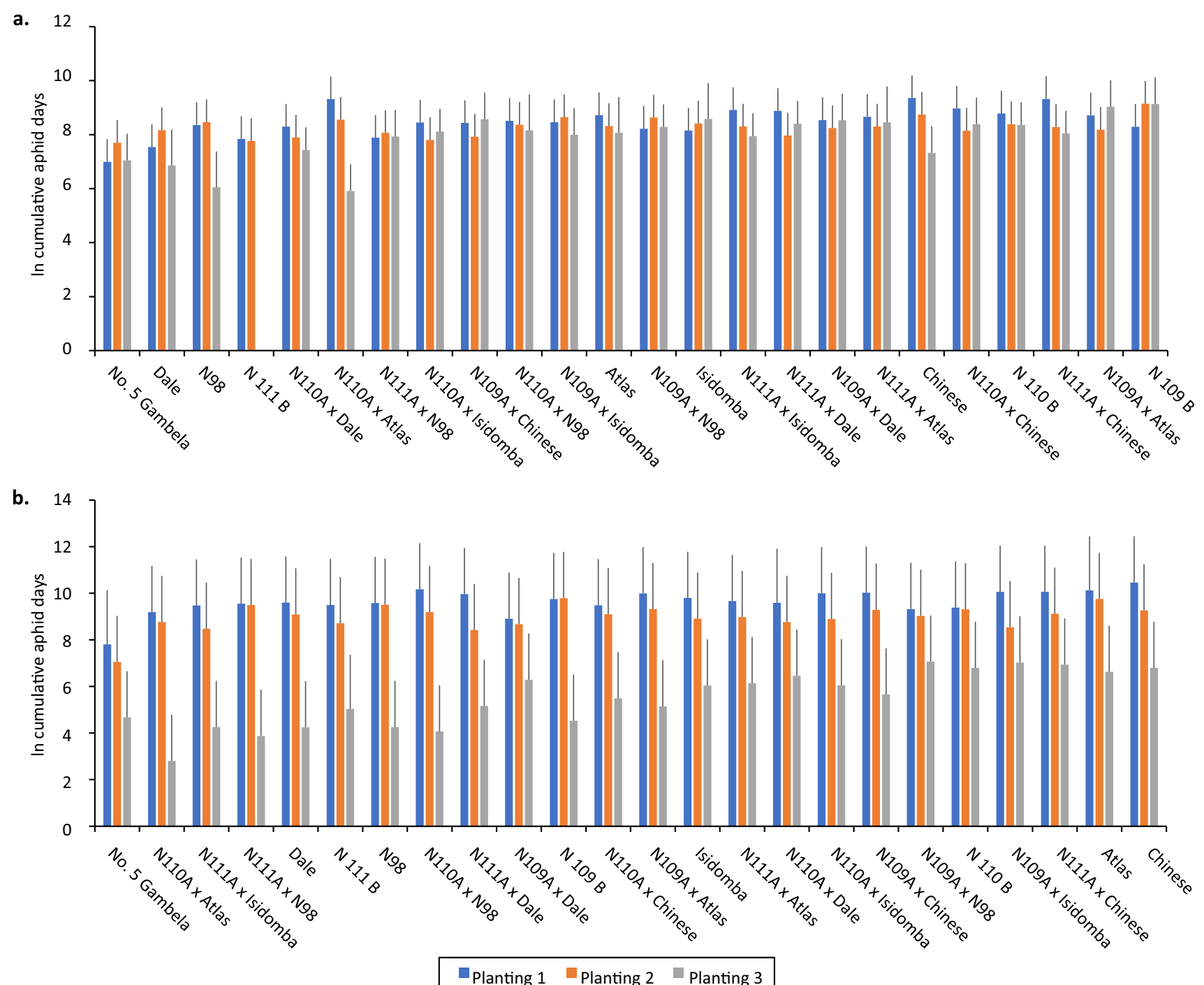

Fig. 3 Average cumulative aphid days (ln scale) for 24 sorghum cultivars sown in April (Planting 1), May (Planting 2), and June (Planting 3), in years a 2016 and b 2017 at Tifton, GA. Error bars represent approximate 95\% confidence intervals; for clarity, only upper bars are shown

be separated statistically except within the third planting. Within Planting 3, cultivars N109A $\times$ N98 and N109A $\times$ Isidomba were among those with the greatest cumulative aphid days, whereas N110A $\times$ N98, N111A $\times$ N98, and $\mathrm{N} 110 \mathrm{~A} \times$ Atlas had the least (Fig. 3b).

\section{Relationships between sugarcane aphids and sorghum juice chemical properties}

Significant environmental and cultivar effects were observed for most sorghum juice chemical properties. These have been reported previously (Uchimiya et al. 2017a,b; Uchimiya and Knoll 2018, 2019a, 2020) and are summarized in Supplemental Tables S1-S4. Correlation analyses revealed negative correlations between sugarrelated traits and aphid damage ratings, particularly in the environments where aphid damage was high (Table 1). Glucose and fructose were significantly negatively correlated with aphid damage in 2015-1 and 2016-2 environments, and glucose was also negatively correlated in the 2015-2 planting. Sucrose showed negative correlations with aphid damage in planting 2015-2 as well as 2017-1 and 2017-2. Total sugars were significantly negatively correlated with aphid damage in four environments - 2015-1, 2015-2, 2017-1, and 2017-2. Brix, which measures total dissolved solids, was negatively correlated with aphid damage ratings in all environments except 2017-3 (Table 1 and Supplemental Fig. S2), when overall aphid damage was very low. Sugar traits were also negatively correlated with cumulative aphid days when the sugarcane aphid infestation was high (Table 2). Glucose and fructose were both correlated with aphid days in the 2016-2 
Table 1 Pearson correlations $(r)$ between aphid damage ratings (relative marginal effect) and various chemical properties of sorghum stem juice in seven environments

\begin{tabular}{|c|c|c|c|c|c|c|c|}
\hline & Environm & & & & & & \\
\hline & $2015-1$ & $2015-2$ & 2015-3 & $2016-2$ & $2017-1$ & $2017-2$ & $2017-3$ \\
\hline & $r$ & & & & & & \\
\hline Glucose & $-0.525^{* *}$ & $-0.480^{*}$ & -0.145 & $-0.578^{* *}$ & -0.373 & -0.007 & -0.276 \\
\hline Fructose & $-0.470^{*}$ & -0.386 & 0.032 & $-0.622^{* *}$ & -0.290 & 0.109 & -0.265 \\
\hline Sucrose & -0.399 & $-0.551^{* *}$ & -0.374 & -0.125 & $-0.661^{* * *}$ & $-0.734^{* * *}$ & 0.006 \\
\hline Total sugars & $-0.500^{*}$ & $-0.602^{* *}$ & -0.346 & -0.360 & $-0.640^{* * * *}$ & $-0.584^{* *}$ & -0.200 \\
\hline Brix & $-0.588^{* *}$ & $-0.695^{* * *}$ & $-0.563^{* *}$ & $-0.458^{*}$ & $-0.620^{* *}$ & $-0.552^{* *}$ & -0.381 \\
\hline trans-Aconitic & $-0.493^{*}$ & $-0.564^{* *}$ & -0.261 & -0.384 & $-0.788^{* * * *}$ & $-0.798^{* * *}$ & -0.083 \\
\hline TOC & $-0.454^{*}$ & -0.269 & -0.402 & -0.379 & $-0.627^{* * * *}$ & $-0.574^{* *}$ & -0.190 \\
\hline $\mathrm{pH}$ & 0.270 & $0.477^{*}$ & $0.426^{*}$ & -0.070 & 0.161 & -0.288 & 0.365 \\
\hline $\mathrm{EC}$ & $0.451^{*}$ & $0.523^{*}$ & 0.194 & $0.448^{*}$ & 0.130 & 0.268 & 0.243 \\
\hline $\mathrm{TN}$ & 0.340 & 0.161 & $0.517^{*}$ & -0.273 & -0.268 & 0.027 & 0.266 \\
\hline EEM abs. 1 & $0.584^{* *}$ & 0.042 & 0.241 & -0.232 & -0.359 & 0.145 & 0.329 \\
\hline EEM abs. 2 & $0.483^{*}$ & 0.399 & 0.140 & 0.108 & $0.637^{* * * *}$ & 0.302 & 0.319 \\
\hline EEM abs. 3 & 0.157 & -0.043 & 0.187 & $-0.432^{*}$ & $-0.686^{* * *}$ & $-0.538^{* *}$ & 0.367 \\
\hline EEM abs. sum & $0.628^{* *}$ & 0.088 & 0.252 & -0.305 & -0.223 & 0.069 & $0.508^{*}$ \\
\hline EEM \% 2 & $0.466^{*}$ & 0.407 & 0.129 & 0.266 & $0.737^{* * *}$ & $0.782^{* * *}$ & 0.064 \\
\hline EEM \%3 & -0.329 & -0.169 & -0.060 & $-0.405^{*}$ & $-0.697^{* * *}$ & $-0.624^{* * *}$ & 0.259 \\
\hline $\mathrm{E}_{\mathrm{pa}}$ & -0.349 & -0.382 & -0.410 & -0.370 & $-0.774^{* * *}$ & $-0.739^{* * * *}$ & -0.084 \\
\hline CV trapezoidal & 0.152 & -0.119 & 0.316 & $-0.574^{* *}$ & $-0.637^{* * *}$ & $-0.570^{* * *}$ & $0.479^{*}$ \\
\hline CV Gaussian & 0.359 & 0.053 & 0.293 & $-0.537^{* *}$ & $-0.706^{* * *}$ & $-0.658^{* * * *}$ & 0.401 \\
\hline
\end{tabular}

Only those properties with at least one significant correlation are shown. Correlations in italic cells become non-significant when the aphid-resistant cultivar No. 5 Gambela is excluded from the analysis. TOC Total organic carbon, $E C$ Electric conductivity, $T N$ Total nitrogen, EEM Fluorescence excitation-emission, $E_{p a}$ Peak anodic potential, $C V$ Cyclic voltammetry

$*, * *, * * *$ indicate significance at $0.05,0.01$, and 0.001 significance levels, respectively environment, whereas sucrose and total sugars were correlated with aphid days in the 2017-1 and 2017-2 plantings. Brix also showed a significant negative correlation with aphid days in the 2016-2 and 2017-2 environments (Table 2).

Juice concentration of trans-aconitic acid also showed significant negative correlations with sugarcane aphid damage ratings and cumulative aphid days in heavily infested environments. trans-Aconitic acid and aphid damage ratings were moderately negatively correlated in the 2015-1 and 2015-2 environments ( $r=-0.493$ and -0.564 , respectively; Table 1 and Supplemental Fig. S2). In the 2017-1 and 2017-2 plantings trans-aconitic acid was strongly correlated with aphid damage rating $(r=-0.788$ and -0.798 , respectively; Table 1 and Supplemental Fig. S2) and also moderately correlated with cumulative aphid days ( $r=-0.578$ and -0.643 , respectively; Table 2$)$. Cultivar No. 5 Gambela had both the highest trans-aconitic acid and lowest damage rating in these environments and could be considered an outlier (Supplemental Fig. S2). Without No. 5 Gambela in the analysis, the correlations are still significant between damage and trans-aconitic acid
(Table 1); however, the correlations between aphid days and trans-aconitic acid become non-significant (Table 2).

Fluorescence components from EEM/PARAFAC also showed some correlations with aphid damage and cumulative aphid days in some plantings. Most notably, the absolute loading of Component 3 (aromatic) was negatively correlated with aphid damage ratings in the 2016-2, 2017-1, and 2017-2 environments (Table 1), and it also correlated negatively with cumulative aphid days in plantings 2017-1, and 2017-2 (Table 2). The percentage of total fluorescence for Component 3 showed similar correlations (Table 1 and Supplemental Fig. S2). Component 2 (tyrosine-like), however, showed some positive correlations with aphid damage ratings in the 2015-1 and 2017-1 plantings (Table 1), and with cumulative aphid days in Plantings 2016-2 and 2017-2 (Table 2). Percentage of EEM/PARAFAC Component 2 was positively correlated with aphid damage in three environments - 2015-1, 2017-1, and 2017-2 (Table 1 and Supplemental Fig. S2), and with cumulative aphid days in the 2016-2, 2017-1, and 2017-2 plantings (Table 2). Again cultivar No. 5 Gambela could be considered an outlier based on extreme values. If it is excluded from the analysis, the 
Table 2 Pearson correlations ( $r$ ) between cumulative aphid days (ln scale) and various chemical properties of sorghum stem juice in four environments

\begin{tabular}{llllr}
\hline \multicolumn{5}{l}{ Environment } \\
\cline { 2 - 5 } & $2016-2$ & $2017-1$ & $2017-2$ & $2017-3$ \\
& $r$ & & & \\
\hline Glucose & $-0.481^{*}$ & -0.129 & -0.203 & -0.160 \\
Fructose & $-0.420^{*}$ & -0.073 & -0.131 & -0.172 \\
Sucrose & -0.238 & $-0.484^{*}$ & $-0.462^{*}$ & 0.087 \\
Total sugars & -0.387 & $-0.419^{*}$ & $-0.472^{*}$ & -0.042 \\
Brix & $-0.425^{*}$ & -0.390 & $-0.437^{*}$ & 0.035 \\
trans-Aconitate & -0.375 & $-0.578^{* *}$ & $-0.643^{* * *}$ & -0.043 \\
TOC & -0.391 & $-0.407^{*}$ & $-0.459^{*}$ & -0.055 \\
EEM abs. 2 & $0.451^{*}$ & 0.399 & $0.498^{*}$ & 0.112 \\
EEM abs. 3 & -0.226 & $-0.506^{*}$ & $-0.505^{*}$ & -0.233 \\
EEM \%2 & $0.419^{*}$ & $0.449^{*}$ & $0.747^{* * *}$ & 0.127 \\
EEM \%3 & -0.307 & $-0.504^{*}$ & $-0.514^{*}$ & -0.291 \\
E & -0.198 & $-0.597^{* *}$ & $-0.606^{* *}$ & -0.150 \\
CV trapezoidal & -0.224 & $-0.596^{* *}$ & $-0.667^{* * *}$ & 0.033 \\
CV Gaussian & -0.166 & $-0.675^{* * *}$ & $-0.705^{* * *}$ & 0.276 \\
\hline
\end{tabular}

Only those properties with at least one significant correlation are shown. Correlations in italic cells become non-significant when the aphid-resistant cultivar No. 5 Gambela is excluded from the analysis. TOC Total organic carbon, EEM Fluorescence excitation-emission, $C V$ Cyclic voltammetry

$*, * *, * * *$ indicate significance at $0.05,0.01$, and 0.001 significance levels, respectively

correlations between Component 2 percentage and aphid damage in 2017-1 and 2017-2 environments are still significant (Table 1), as is the correlation between Component 2 percentage and cumulative aphid days in the 2017-2 planting (Table 2).

Cyclic voltammetry parameters did not correlate with aphid damage ratings in any environments in 2015; however, in the first two plantings of 2017, peak anodic potential $\left(\mathrm{E}_{\mathrm{pa}}\right)$, trapezoidal area, and Gaussian area were all negatively correlated with aphid damage ratings (Table 1) and cumulative aphid days (Table 2). Both trapezoidal and Gaussian peak areas were also negatively correlated with aphid damage ratings in 2016-2 (Table 1). The integrated peak areas (both Gaussian and trapezoidal) were not correlated with aphid days or damage when No. 5 Gambela was excluded, but peak anodic potential $\left(\mathrm{E}_{\mathrm{pa}}\right)$ remained significantly correlated with damage (Table 1).

\section{Stability analysis}

Chemical traits that showed strong correlations with sugarcane aphid damage were subjected to stability analysis to investigate the environmental responses of individual cultivars. For Brix, two cultivars (Dale and No. 5 Gambela) exhibited zero slopes (Table 3), indicating that these cultivars are able to maintain similar levels of Brix despite environmental changes, which in this study were dominated by the level of sugarcane aphid infestation. Sucrose and total sugars (Fig. 4a) showed a similar pattern, with the cultivars Dale, No. 5 Gambela, and Isidomba having zero slopes for these two traits. Monosaccharides (glucose and fructose) were more stable across environments than sucrose or total sugars. For glucose, seven cultivars had zero slopes and for fructose eight cultivars had zero slopes (Table 3). Four cultivars (Chinese, Dale, Isidomba, and No. 5 Gambela) had zero slopes for trans-aconitic acid. Cultivar No. 5 Gambela maintained a very high concentration of this compound in all four environments in which it was grown. Cultivars Dale and Isidomba maintained moderate levels of trans-aconitic acid, and the cultivar Chinese, though stable, had consistently low trans-aconitic acid concentration (Fig. 4b and Supplemental Table S1). The cultivar response of cyclic voltammetry parameters was more variable, with six cultivars having zero slope for trapezoidal peak area and two different cultivars having zero slope for Gaussian peak area (Table 3). Most fluorescence parameters from EEM-PARAFAC did not show a significant interaction between cultivar and environmental index, indicating that all cultivars responded similarly to environment with respect to these parameters. However, PARAFAC component 3 , both percent and absolute, did show an interaction, but the only zero slopes were from the cultivar No. 5 Gambela (not shown).

\section{Discussion}

Correlations among the various chemical traits of sorghum stem juice were previously reported for the 2015 data (Uchimiya and Knoll 2019b) and the 2017 data (Uchimiya and Knoll 2020). In general, the individual sugars, total sugars, Brix, trans-aconitic acid, and TOC were all positively correlated with one another. Other properties including EC, $\mathrm{pH}$, and $\mathrm{TN}$ were negatively correlated with sugars, Brix, TOC, and trans-aconitic acid. The aromatic EEM component (No. 3) was generally positively correlated with sugarrelated traits, whereas the protein-like EEM components (1 and 2) were negatively correlated with sugar-related traits.

Lower aphid damage in the late (June) plantings appears to be a consequence of not only fewer aphid days, but also timing of the infestation in relation to plant growth stage (Uchimiya and Knoll 2019b). After the collapse of the aphid population, it appears that the late-planted crop had sufficient time to recover, produce new growth, flower, and thus accumulate sugars in the stalk. The production of healthy new growth also led to overall lower visual damage ratings, which did not correlate with most juice chemical parameters in the 2015-3 and 2017-3 environments. Within heavily infested 
Table 3 Slopes $(b)$ from stability analysis for selected juice chemical traits in 23 sorghum cultivars grown in seven environments, or four environments for cultivar No. 5 Gambela, with varying levels of sugarcane aphid infestation

\begin{tabular}{|c|c|c|c|c|c|c|c|c|}
\hline Cultivar & $\begin{array}{l}\text { Brix } \\
\text { slope }(b)\end{array}$ & Glucose & Fructose & Sucrose & Total sugars & Trans-aconitic & CV-trap & CV-Gauss \\
\hline Atlas & 0.920 & 0.620 & 0.432 & 1.049 & 0.905 & 0.832 & 1.560 & 0.718 \\
\hline Chinese & 0.980 & 0.593 & 0.186 & 0.805 & 0.815 & 0.509 & 0.295 & 1.447 \\
\hline Dale & 0.210 & 0.405 & 1.166 & -0.140 & -0.210 & 0.192 & 1.272 & 0.578 \\
\hline Isidomba & 0.538 & -0.173 & -0.265 & 0.157 & 0.031 & 0.051 & 1.635 & 0.434 \\
\hline N 109 B & 0.755 & 0.961 & 0.835 & 0.877 & 0.516 & 0.667 & 1.595 & 0.623 \\
\hline N 110 B & 1.006 & 1.186 & 1.240 & 0.816 & 1.051 & 0.995 & 0.457 & 1.045 \\
\hline N $111 \mathrm{~B}$ & 0.920 & 1.955 & 1.768 & 1.228 & 1.028 & 1.324 & 0.614 & 0.822 \\
\hline $\mathrm{N} 109 \mathrm{~A} \times$ Atlas & 1.060 & $\mathbf{0 . 0 3 7}$ & 0.565 & 0.767 & 1.191 & 1.478 & 1.584 & 0.701 \\
\hline N109A $\times$ Chinese & 0.883 & 1.038 & 0.891 & 1.043 & 1.000 & 1.279 & 2.100 & 1.211 \\
\hline N109A $\times$ Dale & 0.846 & 0.402 & 0.442 & 1.312 & 0.920 & 1.001 & 0.891 & 1.215 \\
\hline N109A $\times$ Isidomba & 0.819 & 0.855 & 0.686 & 1.146 & 0.905 & 0.744 & 1.481 & 1.153 \\
\hline $\mathrm{N} 109 \mathrm{~A} \times \mathrm{N} 98$ & 0.880 & 1.096 & 1.212 & 0.888 & 0.719 & 0.647 & 0.869 & 0.815 \\
\hline $\mathrm{N} 110 \mathrm{~A} \times$ Atlas & 1.418 & 1.087 & 1.434 & 0.811 & 1.803 & 1.556 & 1.455 & 0.524 \\
\hline N110A $\times$ Chinese & 1.224 & 1.211 & 1.758 & 0.793 & 1.153 & 0.985 & 0.580 & 1.244 \\
\hline $\mathrm{N} 110 \mathrm{~A} \times$ Dale & 1.104 & 1.622 & 1.608 & 1.819 & 1.157 & 1.518 & 1.059 & 1.170 \\
\hline $\mathrm{N} 110 \mathrm{~A} \times$ Isidomba & 1.238 & 1.030 & 0.945 & 1.256 & 0.927 & 1.104 & 0.769 & 1.120 \\
\hline $\mathrm{N} 110 \mathrm{~A} \times \mathrm{N} 98$ & 1.235 & 0.909 & 0.600 & 1.125 & 1.253 & 0.562 & 0.789 & 1.024 \\
\hline $\mathrm{N} 111 \mathrm{~A} \times$ Atlas & 1.163 & 1.220 & 1.444 & 1.224 & 1.340 & 1.208 & 0.899 & 1.144 \\
\hline N111A $\times$ Chinese & 1.294 & 1.578 & 1.456 & 1.248 & 1.416 & 1.239 & 0.894 & 1.184 \\
\hline N111A $\times$ Dale & 1.028 & 2.014 & 2.173 & 1.188 & 1.503 & 1.042 & 0.266 & 1.407 \\
\hline N111A $\times$ Isidomba & 1.282 & 0.756 & 0.579 & 1.726 & 1.191 & 1.389 & 0.736 & 0.844 \\
\hline $\mathrm{N} 111 \mathrm{~A} \times \mathrm{N} 98$ & 1.211 & 1.500 & 1.663 & 1.148 & 1.319 & 1.354 & 1.265 & 0.689 \\
\hline N98 & 1.265 & 0.765 & 0.991 & 1.106 & 0.986 & 1.490 & 2.115 & 0.737 \\
\hline No. 5 Gambela & 0.060 & 0.766 & 0.379 & -0.093 & 0.103 & 0.538 & 1.955 & 0.492 \\
\hline
\end{tabular}

CV-trap. and CV-Gauss. are trapezoidal and Gaussian integrated peak areas, respectively, from cyclic voltammetry of sweet sorghum juice. Slopes in bold are not significantly different from zero

environments, the negative correlations between aphid damage or aphid days and sugar-related traits demonstrate that resistant or tolerant cultivars are able to maintain sugar production, whereas less tolerant cultivars show reduced sugar accumulation. This result is expected, as aphids feed from the phloem, extracting photosynthate directly from the plant. The reduction in overall photosynthesis caused by aphid feeding (Paudyal et al. 2020) further compounds the reduction in juice sugar content. Stability analysis confirms that the more tolerant cultivars (Dale, Isidomba, and No. 5 Gambela) maintained sucrose and total sugar accumulation despite varying levels of aphid infestation and damage. It is interesting to note that the hybrids derived from Isidomba and Dale did not maintain high sugar concentration across environments (their slopes were closer to 1 ). In this set of cultivars, the inbred cultivars typically flowered later than their hybrids (Knoll et al. 2018); so later flowering might appear to contribute to the stability in juice sugar concentration. However, the inbred line Atlas also flowered late, but it did not maintain high sugar concentration. Glucose and fructose only showed moderate correlations with aphid damage in some environments, and stability analysis indicated zero slopes for several cultivars. Monosaccharide concentration in sorghum stem juice appears to be less affected by sugarcane aphids than are total sugars and sucrose, which is the predominant sugar in mature stems. In young internodes, glucose and fructose are the predominant sugars, whereas sucrose accumulation begins when internode elongation is complete, and the sucrose cleavage activity of sucrose synthase decreases (Hoffmann-Thoma et al. 1996). Sucrose is produced in leaves and is transported via the phloem to the stem parenchyma, where it is unloaded and stored (Mizuno et al. 2016). Aphids feed from the phloem, directly removing sucrose before it reaches the stem.

Other juice components besides sugars were also correlated with aphid damage or cumulative aphid days. The strong negative correlations between trans-aconitic acid and sugarcane aphid damage ratings suggest that this molecule could play a role in the aphid tolerance exhibited by No. 5 Gambela and, to a lesser extent, other cultivars such as 
Fig. 4 Stability analysis plots for $\mathbf{a}$ total sugars and $\mathbf{b}$ transaconitic acid concentration in stem juice of 24 sorghum cultivars planted in seven environments (indicated on the top of each graph). Cultivar No. 5 Gambela was only planted in four environments. Cultivars with zero slopes are indicated with colors (legend); all other cultivars are shown in gray a.

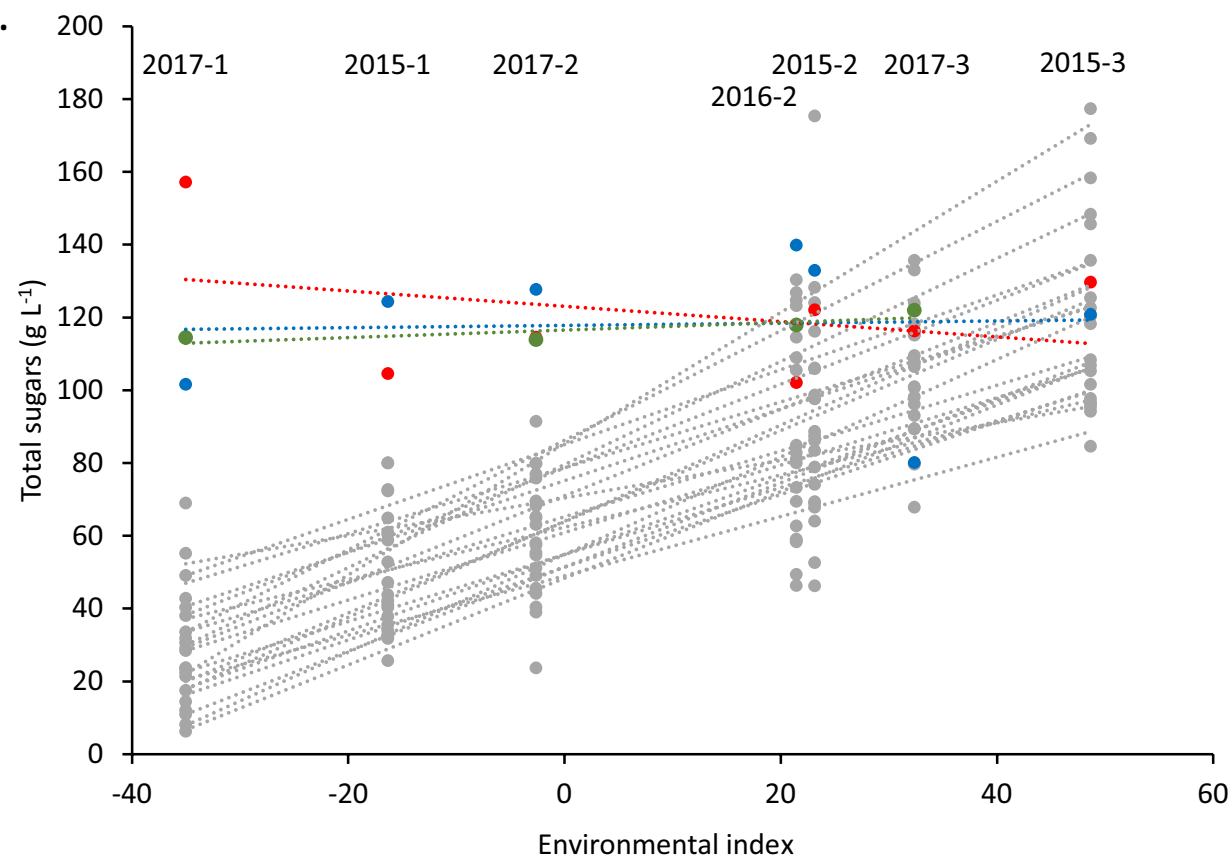

b.

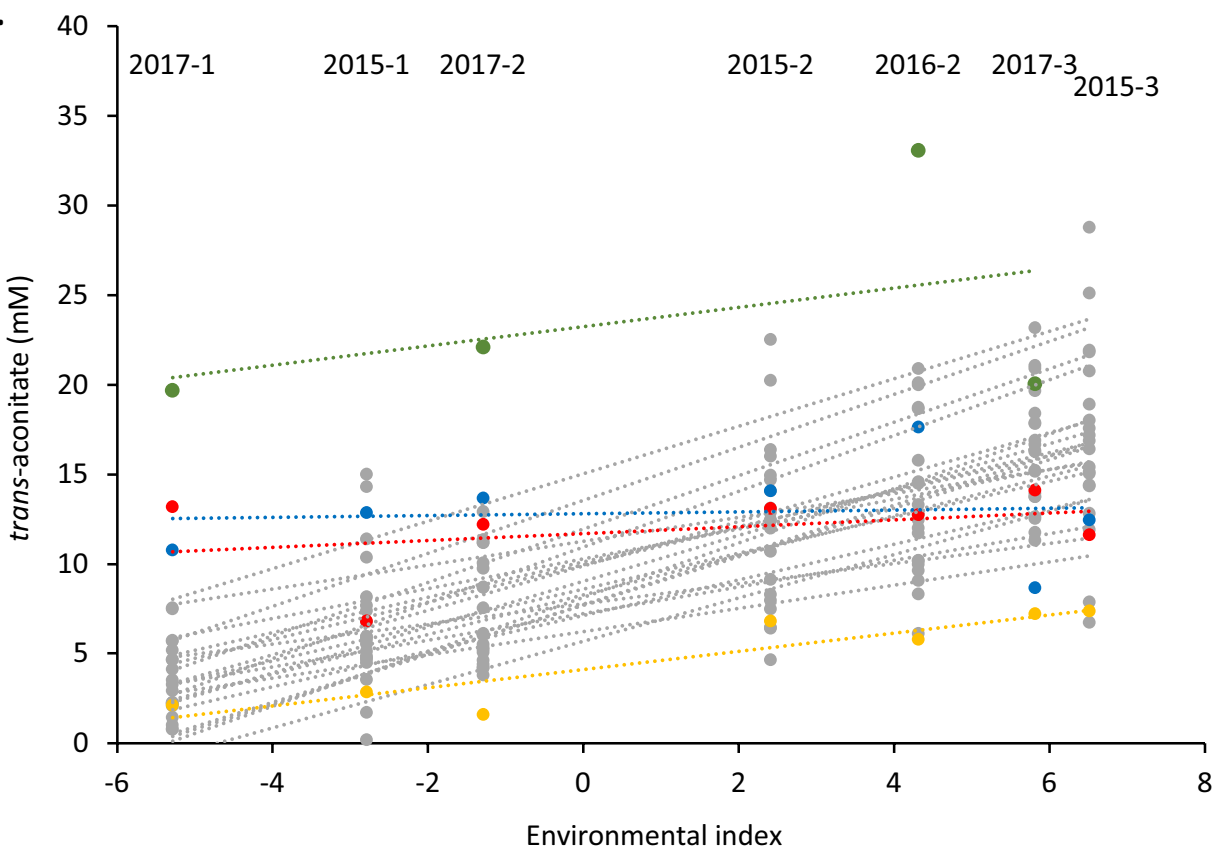

- Chinese - Dale Isidomba 5 Gambela
Isidomba and Dale. These three cultivars also maintained moderate to high levels of this compound across environments. A few previous reports in the literature provide evidence for trans-aconitic acid as a defensive phytochemical against aphids in various grass species, including sorghum (Rustamani et al. 1992a, b; Corcuera 1993).

Fluorescent chemical signatures identified by EEM/PARAFAC also showed some association with aphid damage or cumulative aphid days. Most notably, the percentages of Component 2 (tyrosine-like) and Component 3 (aromatic) showed opposite correlations. Correlations between aphid damage or aphid days and the percentage of Component 2 were positive, whereas those between aphid damage or aphid days and percentage of Component 3 were negative. Absolute values showed similar trends, but the correlations were not always significant. The polyphenolic (aromatic) 
structures detected in juice of No. 5 Gambela appear to be unique to this cultivar, at least among those in this study, and could play a significant role in the strong resistance to sugarcane aphid that is observed in this cultivar. Electrochemical parameters also showed correlations with aphid damage or aphid days in the 2017-1 and 2017-2 environments. A higher $\mathrm{E}_{\mathrm{pa}}$ value indicates electrochemically more recalcitrant structure of electron-donating (reductant) components in sorghum juice (Uchimiya and Knoll 2020). The negative correlation between $\mathrm{E}_{\mathrm{pa}}$ and aphid damage rating suggests multiple chemical pathways against aphids that include polyphenolic antioxidants. The shift in $\mathrm{E}_{\mathrm{pa}}$ indicates different chemical structures of reducing polyphenolic moieties (Uchimiya and Stone 2006). A higher voltage is required to oxidize the polyphenols in No. 5 Gambela than in the other tested cultivars, indicating more recalcitrant and conjugated structural composition. Previous research has demonstrated defensive properties of polyphenols such as apigeninidin, luteolinidin, and their derivatives against fungal infection, insects, and abiotic stress in sorghum (Lo et al. 1999; Dicko et al. 2005). Dreyer et al. (1981) also reported that the polyphenol procyanidin isolated from sorghum had anti-feeding activity against biotype $\mathrm{C}$ greenbug aphid (Schizaphis graminum) in a bioassay. These or similar compounds may also be active against sugarcane aphids in No. 5 Gambela, as stress-response pathways often overlap. Using a metabolomics approach, Tugizimana et al. (2019) identified changes in multiple pathways including flavonoid synthesis and tryptophan metabolism in sorghum in response to pathogen attack. In addition, molecules derived from the tryptophan pathway, such as gramine and benzoxazinones, are also known to function in plant defense against pathogens and insects (Kokubo et al. 2017), though these have not yet been identified in sorghum.

\section{Conclusions}

Sugarcane aphid damage ratings were found to correlate moderately with cumulative aphid days in most environments. Heavy feeding by sugarcane aphids was associated with reductions in Brix and concentrations of total sugars and TOC in sorghum stem juice. Under moderate-to-heavy infestation, the more resistant/tolerant cultivars (those with less visible damage - Dale, Isidomba, and No. 5 Gambela) were able to maintain higher total sugar content and sucrose than more susceptible cultivars. Monosaccharides (glucose and fructose) were less affected by sugarcane aphid damage. In some environments, very strong correlations were observed between aphid damage rating or cumulative aphid days and juice trans-aconitic acid concentration, suggesting that this metabolite may function as a general aphid tolerance mechanism in sorghum, or perhaps it could be used as a biochemical marker to select for tolerant cultivars. Further studies, such as bioassays, are needed to confirm the role of trans-aconitic acid in aphid resistance/tolerance and to determine the mechanism (i.e., antibiosis, antixenosis, or tolerance) of host resistance. Fluorescent and electrochemical juice properties also showed some correlations with aphid damage ratings and cumulative aphid days; however, these correlations were strongly influenced by the aphid-resistant control cultivar, No. 5 Gambela. It is not yet clear if these antioxidant molecules are responsible for the high level of sugarcane aphid resistance seen in this cultivar, but they offer opportunities for further investigation.

Supplementary Information The online version contains supplementary material available at https://doi.org/10.1007/s11829-021-09855-z.

Acknowledgements The authors would like to thank Trevor Perla and Hongliang Wang (USDA-ARS) for maintenance of field plots and other technical assistance.

Author contribution JEK planned and conducted the field experiments. JEK and KHS collected aphid data and juice samples. MU conducted all juice chemical analyses. JEK and MU analyzed the data. All authors contributed to writing and editing the manuscript.

Funding This research was funded by USDA-ARS base funds and Areawide Pest Management Project 6048-21220-018-09-S.

Data availability The datasets generated and analyzed during this study are available in the Supplementary Material of this manuscript.

\section{Declarations}

Conflict of interest The authors declare no competing interests.

Disclaimer Mention of trade names or commercial products in this publication is solely for the purpose of providing specific information and does not imply recommendation or endorsement by the US Department of Agriculture. USDA is an equal opportunity provider and employer.

Open Access This article is licensed under a Creative Commons Attribution 4.0 International License, which permits use, sharing, adaptation, distribution and reproduction in any medium or format, as long as you give appropriate credit to the original author(s) and the source, provide a link to the Creative Commons licence, and indicate if changes were made. The images or other third party material in this article are included in the article's Creative Commons licence, unless indicated otherwise in a credit line to the material. If material is not included in the article's Creative Commons licence and your intended use is not permitted by statutory regulation or exceeds the permitted use, you will need to obtain permission directly from the copyright holder. To view a copy of this licence, visit http://creativecommons.org/licenses/by/4.0/. 


\section{References}

Andrzejewski B, Eggleston G, Powell R (2013) Pilot plant clarification of sweet sorghum juice and evaporation of raw and clarified juices. Ind Crops Prod 49:648-658

Bowling RD, Brewer MJ, Kerns DL, Gordy J, Seiter N, Elliott NE, Buntin GD, Way MO, Royer TA, Biles S, Maxson E (2016) Sugarcane aphid (Hemiptera: Aphididae): a new pest on sorghum in North America. J Integr Pest Manag 17(1):12-13

Broadhead DM, Coleman OH (1973) Registration of Dale sweet sorghum. Crop Sci 18:776

Corcuera LJ (1993) Biochemical basis for the resistance of barley to aphids. Phytochemistry 33(4):741-747

Davila-Gomez FJ, Chuck-Hernandez C, Perez-Carrillo E, Rooney WL, Serna-Saldivar SO (2011) Evaluation of bioethanol production from five different varieties of sweet and forage sorghums (Sorghum bicolor (L) Moench). Ind Crops Prod 33:611-616

Dicko MH, Gruppen H, Barro C, Traore AS, Van Berke WJH, Voragen AGJ (2005) Impact of phenolic compounds and related enzymes in sorghum varieties for resistance and susceptibility to biotic and abiotic stresses. J Chem Ecol 31(11):2671-2688

Dreyer DL, Reese JC, Jones KC (1981) Aphid feeding deterrents in sorghum: bioassay, isolation, and characterization. J Chem Ecol 7(2):273-284

Eberhart SA, Russell WA (1966) Stability parameters for comparing varieties. Crop Sci 6:36-40

Gorz HJ, Haskins FA, Johnson BE (1990) Registration of 15 germplasm lines of grain sorghum and sweet sorghum. Crop Sci 30:762-763

Haar PJ, Bowling R, Gardner WA, Buntin GD (2018) Epizootics of the entomopathogenic fungus Lecanicillium lecani (Hypocreales: Clavicipitaceae) in sugarcane aphid (Hemiptera: Aphididae) populations infesting grain sorghum in Georgia and Texas. J Entomol Sci 53(1):104-106

Haar PJ, Buntin GD, Jacobson A, Pekarcik A, Way MO, Zarrabi A (2019) Evaluation of tactics for management of sugarcane aphid (Hemiptera: Aphididae) in grain sorghum. J Econ Entomol 112(6):2719-2730

Harris-Shultz K, Ni X (2021) A sugarcane aphid (Hemiptera: Aphididae) "super-clone" remains on US sorghum and Johnsongrass and feeds on giant miscanthus. J Entomol Sci 56(1):43-52

Hills FJ, Lewellen RT, Skoyen IO (1990) Sweet sorghum cultivars for alcohol production. Calif Agric 44(1):14-16

Hoffmann-Thoma G, Hinkel K, Nicolay P, Willenbrink J (1996) Sucrose accumulation in sweet sorghum stem internodes in relation to growth. Physiol Plant 97:277-284

Knoll JE, Anderson WF, Harris-Shultz KR, Ni X (2018) The environment strongly affects estimates of heterosis in hybrid sweet sorghum. Sugar Tech 20:261-274

Knoll JE, Harris-Shultz KR, Ni X (2019) Update on sugarcane aphid genetics, management in sweet sorghum, and breeding for resistance. In: Lima I, Egglestson G, Clayton C (eds) Advances in sugar crops processing and conversion, vol 2. May 15-18, 2018. New Orleans, LA, USA, pp 172-186

Kokubo Y, Nishizaka M, Ube N, Yabuta Y, Tebayashi S, Ueno K, Taketa S, Ishihara A (2017) Distribution of the tryptophan pathway-derived defensive secondary metabolites gramine and benzoxazinones in Poaceae. Biosci Biotechnol Biochem 81(3):431-440

Lo S-CC, De Verdier K, Nicholson RL (1999) Accumulation of 3-deoxyanthocyanidin phytoalexins and resistance to Colletotrichum sublineolum in sorghum. Physiol Mol Plant Pathol $55: 263-273$
Mizuno H, Kasuga S, Kawahigashi H (2016) The sorghum SWEET gene family: stem sucrose accumulation as revealed through transcriptome profiling. Biotechnol Biofuels 9:127

Nibouche S, Costet L, Holt JR, Jacobson A, Pekarcik A, Sadeyen J, Armstrong JS, Peterson GC, McLaren N, Medina RF (2018) Invasion of sorghum in the Americas by a new sugarcane aphid (Melanaphis sacchari) superclone. PLoS One 13:e0196124

Paudyal S, Armstrong JS, Giles KL, Hoback W, Aiken R, Payton ME (2020) Differential responses of sorghum genotypes to sugarcane aphid feeding. Planta 252:14

Paudyal S, Armstrong JS, Harris-Shultz KR, Wang H, Giles KL, Rott PC, Payton ME (2019) Evidence of host plant specialization among the U.S. sugarcane aphid (Hemiptera: Aphididae) genotypes. Trends Entomol 15:47-58

Ruppel RF (1983) Cumulative insect-days as an index of crop protection. J Econ Entomol 76:375-377

Rustamani MA, Kanehisa K, Tsumuki H (1992a) Aconitic acid content of some cereals and its effect on aphids. Appl Entomol Zool 27:79-87

Rustamani MA, Kanehisa K, Tsumuki H, Shiraga T (1992b) Further observations on the relationship between aconitic acid contents and aphid densities on some cereal plants. Bull Res Inst Bioresour Okayama Univ 1:9-20

Seiter NJ, Miskelley AD, Lorenz GM, Joshi NK, Studebaker GE, Kelley JP (2019) Impact of planting date on Melanaphis sacchari (Hemiptera: Aphididae) population dynamics and grain sorghum yield. J Econ Entomol 112(6):2731-2736

Shah DA, Madden LV (2004) Nonparametric analysis of ordinal data in designed factorial experiments. Phytopathology 94:33-43

Sharma HC, Bhagwat VR, Daware DG, Pawar DB, Munghate RS, Sharma SP, Kumar AA, Reddy BVS, Prabhakar KB, Gadakh ASS, SR, (2014) Identification of sorghum genotypes with resistance to the sugarcane aphid Melanaphis sacchari under natural and artificial infestation. Plant Breed 133:36-44

Singh BU, Padmaja PG, Seetharama N (2004) Biology and management of the sugarcane aphid, Melanaphis sacchari (Zehntner) (Homoptera: Aphididae), in sorghum: a review. Crop Prot 23:739-755

Szczepaniec A (2018) Assessment of a density-based action threshold for suppression of sugarcane aphids, (Hemiptera: Aphididae), in the Southern High Plains. J Econ Entomol 111:2201-2207

Tugizimana F, Djami-Tchatchou AT, Steenkamp PA, Piater LA, Dubery IA (2019) Metabolomic analysis of defense-related reprogramming in Sorghum bicolor in response to Colletotrichum sublineolum infection reveals a functional metabolic web of phenylpropanoid and flavonoid pathways. Front Plant Sci 9:1840

Uchimiya M, Knoll JE (2018) Prediction of carboxylic and polyphenolic chemical feedstock quantities in sweet sorghum. Energy Fuel 32:5252-5263

Uchimiya M, Knoll JE (2019a) Accumulation of carboxylate and aromatic fluorophores by a pest-resistant sweet sorghum (Sorghum bicolor (L.) Moench) genotype. ACS Omega 4:20519-20529

Uchimiya M, Knoll JE (2019) Rapid data analytics to relate sugarcane aphid [(Melanaphis sacchari (Zehntner)] population and damage on sorghum (Sorghum bicolor (L.) Moench). Sci Rep 9:370. https://doi.org/10.1038/s41598-018-36815-0

Uchimiya M, Knoll JE (2020) Electroactivity of polyphenols in sweet sorghum (Sorghum bicolor (L.) Moench) cultivars. PLoS One 15(7):4509

Uchimiya M, Knoll JE, Anderson WF, Harris-Shultz KR (2017a) Chemical analysis of fermentable sugars and secondary products in 23 sweet sorghum cultivars. J Agric Food Chem 65:7629-7637 
Uchimiya M, Knoll JE, Harris-Shultz KR (2017b) Electrochemical evaluation of sweet sorghum fermentable sugar bioenergy feedstock. ACS Sust Chem Eng 5:7352-7364

Uchimiya M, Stone AT (2006) Redox reactions between iron and quinones: thermodynamic constraints. Geochim Cosmochim Ac 70:1388-1401

Winberry JJ (1980) The sorghum syrup industry: 1854-1975. Agric Hist 54(2):343-352
Publisher's Note Springer Nature remains neutral with regard to jurisdictional claims in published maps and institutional affiliations. 